\title{
Internet clinical trials: examining new disciplinary experiments in health care.
}

\author{
Jenny Advocat (Monash University, Australia)
}

Internet-based clinical trials are the latest example of how technology is involved in altering the relationships between medical research institutions and society. This has the potential to change drastically the creation, delivery and access to health care research. An anthropology of science, technology and medicine is well-suited to examine the ways in which relationships (such as doctor-patient) are rearticulated in light of the deployment of new technologies in biomedicine. This paper examines how internet-based clinical trials may create sociotechnical networks that form new kinds of subjects. Drawing on actor network theory, I discuss how the internet is co-opted for health research as an experimental disciplinary technology to constitute, normalize and shape the conduct of nomadic consumer-subjects for the purposes of developing new regimes of governing the health of populations.

In this paper I will examine the implications of conducting Randomized Controlled Trials (RCTs) on the internet. Internet-based clinical trials are one of the latest examples of how technology is involved in altering the relationships between medical institutions and society with the potential to change drastically the creation, delivery and access to clinical research. An anthropology of science, technology and medicine is well suited to examine the ways in which relationships are rearticulated in light of the deployment of new technologies in biomedicine. Moreover, anthropology is well matched with science and technology studies, whose proponents have shown again and again the ways in which particular values and ideologies are built into new technologies (see, for example, Anderson 2002; Dumit 2004; Forsythe 2001; Haaken 1999). Unlike more traditional anthropological research projects, there is no specific 'field' from which to understand the interactions between health care researcher, consumer and provider. In this paper I will discuss the ways in which internet-based clinical trials may create socio-technical networks that form new kinds of subjects. I will start by describing my role, as a $\mathrm{PhD}$ student and medical anthropologist working from within medicine, and how this affects my methodology. Following this brief introduction of my own role in the project, I explain what a RCT is and its role in the growing field of evidence-based medicine (EBM). ${ }^{1}$ I use Actor Network Theory (ANT), where the stakeholders are understood to be part of a network which also includes non-human actors (such as the internet, the computers and the particular

\footnotetext{
1 The term evidence-based medicine is itself not agreed upon as the best name for this social movement. The term 'medicine' implies the domain of 'doctors', thereby excluding many allied health professionals for whom EBM is also relevant. Often, writers in evidence-based medicine will make note of this discrepancy between the term medicine and the application of evidence-based practice, but chose for simplicity to maintain the term 'medicine'. I will use the terms 'medicine' and 'practice' interchangeably in this paper.
} 
intervention on trial), to argue that online RCTs may work to create new sociotechnical networks that form different kinds of subjects in health research.

Though my training is in medical anthropology, the $\mathrm{PhD}$ project which I started in 2004 at Monash University is a $\mathrm{PhD}$ in Medicine. The question of the 'feasibility of online trials' was conceived by researchers at the Monash Institute of Health Services Research (MIHSR) in part by my supervisor, who is a physiotherapist and proponent of EBM, through her work as the director of the Australasian Cochrane Centre. The grant application for this project, ${ }^{2}$ entitled A Novel Internet-based Clinical Trial Service asks about the 'feasibility' of conducting RCTs online and is funded by the Australian Research Council, Southern Health, a network of health care services covering southeast Melbourne, and Monash University. The word anthropology is not used once in the grant application, nor is the general concept of social science. I am enrolled in the Medical Faculty at the Monash Medical Centre, the only anthropologist amongst mostly medical researchers. My role in this project was very loosely described as looking at the effects of conducting RCTs online for the various people involved. I approach my fieldwork like Sarah Pink, who writes, '...fieldwork can be seen as an activity that is intermingled with other aspects of life and distinguishable only when drawn out of this web of interconnected narratives' (Pink 2000: 99).

RCTs are often referred to as the 'gold standard' method for examining the effects of different treatments and are therefore the backbone of evidence-based health care. ${ }^{3}$ The goal of the project - to determine the feasibility of doing RCTs online - can be understood only in the wider context of clinical research, which is increasingly reliant on what is known as 'evidence based medicine'. This term was coined in the 1980s at McMaster University in Canada. This term is summarized by Sackett, a well-known proponent of EBM, and colleagues. They explain, 'EBM is the conscientious, explicit, and judicious use of current best evidence in making decisions about the care of individual patients. The practice of evidence-based medicine means integrating individual clinical expertise with the best available external clinical evidence from systematic research' (Sackett et al 1996: 71). This clear and well-articulated definition hides the many controversies that have arisen with the increasing uptake of EBM and its associated practices around the translation of evidence into practice, the problems around generalizing and universalizing trial results into local practices and contexts, and many others.

The value of conducting RCTs online is often articulated, in biomedical literature and by proponents of EBM, in terms of increasing the use and availability of an evidencebased approach to clinical research and practice. Of course, the move to incorporate

\footnotetext{
${ }^{2}$ The grant was written by five researchers and submitted in 2001, prior to my own arrival in the department.

${ }^{3}$ Sociologist Evelleen Richards defines an RCT:

'In the randomized... controlled trial, patients at a comparable stage and site of disease are randomly allocated (for example, by the toss of a coin) to different treatments, one of which is the therapy in question, and the other of which may be the best available standard therapy or an inert placebo (a dummy pill made to look and taste like the substance under evaluation). The group receiving the standard therapy or placebo is the control group; the group receiving the experimental therapy is evaluated by a statistical comparison of the responses of the experimental and control groups' (Richards 1991: 29).
} 
new technologies into current biomedical research practices is not novel and has been developing in response to a variety of perceived needs and in various contexts. This specific case study, of using the internet to conduct medical research, is but one way in which this relationship is being played out. Online RCTs are being used to test the efficacy of a variety of treatments, from drug testing to psychological treatments. Usually, for trials testing drug treatments with physiological outcome measures, the data is entered into an online data collection system by the health professional during the participant's scheduled visit. However, there are also trials whereby participants self-report and directly enter their own data online, without having to visit their physician or other health care professional. This data can then either be emailed by the participants to the researchers for data entry or entered directly by the participant into the data collection system. An example of this kind of self-reporting is in an online trial for the treatment of panic disorder, where the outcome measures are all based on participants' self-reporting through psychological questionnaires. This is novel, but it can be argued, not altogether different to our relationship with the telephone. This paper should be seen as part of the wider discussion around the interaction between humans and technologies but as specifically grounded through the exploration of the increasing reliance on information technologies within clinical research, particularly RCTs conducted within the framework of evidence-based practice.

The proliferation of RCTs and their increasing importance to health care research and practice are situated within a particular framework, that of neo-liberalism, where particular types of standardizations and particular kinds of evidence are valued over others. I propose that the shift toward online research is part of the practice of EBM which Timmermans and Berg (2003) argue sits within the broader ideology of standardization, whereby standards are agents involved in the articulation of power relations between various actors. As standards are developed within the context of EBM, participants in trials may become embodied in new ways, whereby the responsibility and expectations of both researcher and participant may change. While I see this as a real shift in the practice of clinical medicine and research, I stress that these shifts can be understood as just one component of a broader neo-liberal agenda. In their article about the relationship between the production of a certain type of patient through the development of patient-centred medical records, Berg and Harterink argue that this very evolution of patient-centred records 'actively feeds into the production of the bodies that populate medicine' (2004: 23). ${ }^{4}$ The authors go on to point out the possibilities of a new, digital subjectivity, whereby subjects become '... de-centered, dispersed and multiplied...' (ibid: 24). Accordingly, my aim is to understand the role of online RCTs from within the context of evidence based practice, and argue that by conceptualizing the online trial with the tools provided by ANT, the ways in which conducting RCTs online has the potential to shift notions of participant subjectivity and change the expectations of participants becomes clearer.

\footnotetext{
${ }^{4}$ In a fascinating article describing the shift from individual doctors maintaining their own patients' medical records to a more centralized kind of record-keeping organized at the hospital level, Berg and Harterink (2004) argue that 'The record's new shape and functioning... is fundamentally intertwined with the new shape that both the patient's body and the medical institutions acquire' (2004: 15).
} 
I call the online RCT itself the centre of calculation, where information in the form of inscriptions is accumulated as part of a network, and following Latour (1987), these inscriptions are used to represent particular aspects of the participants in ways, as Bloomfield argues, 'which can be gathered, mobilized, archived, coded and displayed' (Bloomfield 1991: 711). The rationale for the accumulation of information can be understood through Foucault's notion of governmentality, as interpreted by Dean (1999). Governmentality can be used to contextualize the use of online RCTs in an attempt to, as Dean says, 'shape rationally human conduct' (ibid: 11). Foucault's notion of bio-politics, explained by Dean as 'a form of politics entailing the administration of the processes of life of populations', describes a way in which populations are governed, counted, represented and accounted for (ibid: 99). The context within which online RCTs are put forth as being important and worthwhile stems from a specific rationality of neo-liberalism, in which the individual becomes responsible for him/her self and self-regulation is guided by the clearly articulated rules of appropriate conduct. These rules are defined by experts who are translating their expert knowledge into standards through the practice of evidence-based medicine.

ANT allows us to define the characteristics of an RCT only by way of understanding the relationships between the people and other elements that comprise it. Following Bloomfield (1991), who drew a parallel between inscription devices and information systems, I define the computer, as it is used in online RCTs, as an inscription device, which works to turn information, in this case data given by participants pertaining to the trial, into statistical information. The inscription device sits within a network of alliances. One of ANT's strengths is its ability to recognize the agency of not only the people in the network but also the non-human entities. Networks are said to be heterogeneous, whereby they can be read as scripted. The people as well as the machines have 'scripts', roles they are expected to play, and each entity relies on others to play their assigned roles. ${ }^{5}$ Networks are relational; they are alive, and are in constant motion, requiring continued maintenance in order for the stakeholders to translate their interests into action. In the case of online RCTs, the heterogeneous group includes participants, trialists, clinicians, IT support workers, university servers where the data is stored (including the security system that it uses), software (such as Adobe Acrobat or word processing programs that participants must have access to in order to read documents during the trial) and databases to collect the data as it is received from the participant.

From the centre of calculation, the online RCT, behaviour becomes monitored on the periphery. Online RCTs extend the trial into the participants' homes and into their personal, daily lives, in potentially new ways. With the advent of internet technologies, distance does not necessarily create a problem for the movement of information. In this way, online RCTs may be increasingly mobile, and the inscriptions increasingly immutable, and so information can be brought from a peripheral point, to the centre, where the information may then be codified, or standardized, with increasing reliability. Similarly, participants may become less

\footnotetext{
5 The way that actors sometimes resist this role assignment has been acknowledged (Star 1991). Resistance becomes a more important concept to consider when analysing an actual online trial. In order to recognize the places where both researcher and participant actively change or challenge the network, and in what ways, the analyst must be sensitive to these places of resistance.
} 
linked to specific and particular geographical spaces, thereby potentially becoming a new kind of nomadic-consumer.

Online RCTs fit well into the universalizing mentality of EBM, where standardizations work to shift the roles and responsibilities of the people involved. With increasing standardization, the collection of information at the centre may work to change results and action at the periphery. Using online RCTs enables a new form of 'action at a distance' (Latour 1987), where participants' activities are monitored and their behaviour shaped in new ways. ${ }^{6}$ As such, Actor Network Theory is not so much a theory as a methodology, which is best used to examine practices; and in practice there are always unintended consequences, resistances, and places where stakeholders' interests are not perfectly translated (Latour 1999). Consequently, observing the different ways online RCTs develop and unfold, not only enables us to trace the trajectory of multiple, emergent networks but also to identify and document places of resistance.

To continue introducing the way ANT may work in understanding the implications of doing RCTs online, I will use an example from my department. A colleague will be conducting an RCT to investigate, in his words, 'the most effective media for delivering information regarding prostate cancer screening, 7 Part of this trial will be placed online; those who participate via the Internet will be asked to read the 'informed consent' forms over the web and to give their consent to joining the trial from their own homes. In doing so, participants are enrolled into a heterogeneous actor-network that is comprised of other humans, i.e. the trialist, the researcher and other participants, as well as non-human agents: the computer, the internet, the trial itself, and the database behind the website (where information is processed, categorized and stored). ANT will allow an understanding of the ways in which the relations between these human and non-human actors affect the networks that form and the particular inscriptions that develop.

I conceptualize my research as multi-sited and approach my department, MIHSR, as my main field site. My colleagues, physicians and health service researchers, are mostly interested in furthering research and educating other health care professionals on the subject of evidence-based practice. Working from within medicine allows me access to trials like the one described above. In a way, this context provides a variation on the question of how to 'study up'. I ask instead, how can I study up, from within? MIHSR is one site from which I can elicit information to develop an understanding of the role of RCTs in evidence-based practice, and what role new technologies, like the internet, will play in evidence-based practice in the future. Other sites are defined through my participation in activities and events at MIHSR, such as attending short courses and symposia where I find insights into the kinds of ideas and values of evidence-based practice. Additionally, participant observation with a group of researchers currently conducting an internet-based RCT for treatment for panic disorder will allow me to develop insights into the perspectives of the researchers who engage in research mediated by new technologies. By conceptualizing this research as multi-sited, I am able to trace the construction of specific networks that form between

\footnotetext{
${ }^{6}$ Although I am describing a type of surveillance, the process does not necessarily involve a passive participant. The participants can be conceptualized as active and involved in the trial, using it for their own ends and changing its course with their participation.

${ }^{7}$ D. Illic, personal communication, February 10, 2003.
} 
dispersed groups of people, all working in various branches of health services, and explore the way they conceptualize working with the internet toward their goals of better health care through evidence based practice.

Conducting RCTs online has much broader implications than simply changing the format of providing information about the trial to participants and receiving their informed consent. The above trial is an interesting yet restricted example. Online RCTs have the potential to change clinical research in much more drastic ways. Ultimately, entire RCTs can be conducted where the participant does not have to leave his or her home. Assuming access to a computer, ${ }^{8}$ the participant will be recruited via a website or internet-based advertisement and can enroll, via the web, into a trial. The implications of the increased ease with which participants are asked to self-diagnose and locate for themselves, current trials that they may enter mirrors the trend in the United States of direct-to-consumer advertising of pharmaceutical products. The effect such activities have on participants could be read through an analysis of self-care and the notion of responsibility of individuals caring for their own health and being a responsible consumer.

Following recruitment, potential participants will be checked for eligibility. Informed consent, as shown above, could then be obtained and the participants would be randomized into a particular intervention. Delivery of the intervention could, depending on the specifics of the treatment being evaluated, be approached in an online format, and data could be entered throughout the trial from the participant's home computer. It is here that the notion of self-care is most explicitly played out in online RCTs implying an increasing responsibility on the part of the participant. However, as the prospect of trials run completely online becomes more mundane, trials may reach increasingly larger numbers of people. And, in this way, the administration and monitoring of a population's health becomes increasingly adaptable. So, while the mandate for increasing self-care is promoted, the ability to monitor a population is likewise increasing, creating a new atmosphere for the care of participants in research and by extension, patients. From their enrollment into an online RCT, participants become responsible for their participation at all stages throughout the trial, in ways that may be different from enrollment in a traditionally run RCT. The idea of clinical research where the participant is never seen is novel and its implications are many, for fields across the health disciplines from psychology to cardiology.

Paul Rabinow (1992) speaks to shifting subjectivities, as computers become part and parcel of medical practice. He discusses aspects of the Genome Project but his comments apply here to the implications of online medical research. I am interpreting the following quotation as alluding to concepts of both governmentality, where individuals are shaped through the control of populations, and to ANT, in that it illustrates the way in which computers play an active role in a network that is comprised also of humans. He says,

'Through the use of computers, individuals sharing certain traits or sets of traits can be grouped together in a way that not only decontextualizes

\footnotetext{
8 Access to a computer cannot be assumed. EBM proponents hope to reach a typically underrepresented population (i.e. people with low socio-economic status, rural populations and developing countries) through online RCTs. This goal is complicated and compromised by the low levels of access, for these populations, to technologies that we, in the developed world, take for granted.
} 
them from their social environment but also is nonsubjective in a double sense: it is objectively arrived at, and does not apply to, a subject in anything like the older sense of the word (that is, the suffering, meaningfully situated integrator of social, historical and bodily experiences). Computerized series dissolve the traditional subject and retain only abstract givens as part of factors in a series. The target is not a person but a population at risk' (1992: 243).

Rabinow describes a shift in the way humans are monitored that is reminiscent of the shift I have described above with the move to conduct RCTs online. In doing so, biomedicine may be further decontextualizing medical research, and, as Rabinow describes above, thereby altering the very subjectivity of participants. Instead of simply creating individuals with our own particular health issues, we are becoming populations that need to be monitored. At the same time, society demands that as individuals we take an increasingly rigorous interest in our own self-care and are increasingly responsible for our consumption of medical goods (including practices such as the RCT). I will be examining the practices of online RCTs, from within the context of EBM, as it is played out in particular sites as they evolve and interpreting them through an anthropological lens, informed by methodologies whereby the relationships between technologies and human actors are taken seriously and understood to affect and be affected by the networks in which they are enrolled.

\section{References}

Anderson W. 2002. Postcolonial technoscience. Social Studies of Science 32: 643-58.

Berg M. \& P. Harterink. 2004. Embodying the patient: records and bodies in early 20th century US medical practice. Body and Society 10: 13-41.

Bloomfield B. 1991. The role of information systems in the UK National Health Service: action at a distance and the fetish of calculation. Social Studies of Science 21: 701-34.

Dean, M. 1999. Governmentality. London: Sage.

Dumit J. 2004. Picturing personhood: brain scans and biomedical identity. Oxford: Princeton University Press.

Forsythe D. 2001. Studying those who study us. Stanford: Stanford University Press.

Hakken D. 1999. Cyborgs@Cyberspace: an ethnographer looks to the future. London: Routledge.

Latour B. 1987. Science in action: how to follow scientists and engineers through society. Cambridge, Mass.: Cambridge University Press.

Latour B. 1999. On recalling ANT. In Actor Network Theory and After (eds). Law, J. \& J. Hassard 15-25. Oxford: Blackwell.

Pink S. 2000. 'Informants' who come 'home'. In Constructing the field: ethnographic fieldwork in the contemporary world, (ed) V. Amit. London: Routledge.

Rabinow P. 1992. Artificiality and enlightenment: from sociobiology to biosociality. In Incorporations, (eds), Crary, J. and Kwinter, S. 234-52. New York: Zone.

Richards E. 1991. Vitamin $C$ and cancer: medicine or politics? New York: St. Martin's Press. 
Sackett D., et al. 1996. Evidence-based medicine: what it is and what it isn't. British Medical Journal 312: 71-2.

Star, S. L. 1991. Power, technologies and the phenomenology of conventions: on being allergic to onions. In A sociology of monsters: essays on power, technology and domination (ed) Law, J. 25-56. London: Routledge.

Timmermans S, \& Berg M. 2003. The gold standard: an exploration of evidencebased medicine and standardization in health care. Philadelphia: Temple University Press.

\section{About the author}

I am currently in my third year as a $\mathrm{PhD}$ Candidate in the Faculty of Medicine at the Monash Institute of Health Services Research, Monash University in Melbourne, Australia. I am interested in approaching the work of health services research and evidence based practice, within which online randomized controlled trials are developed and implemented, by drawing upon medical anthropology and science and technology studies. 